\title{
Marchetto of Padua's Theory of Modal Ranges
}

\author{
Jay Rahn, York University (Toronto)
}

Marchetto of Padua's formulation of modal ranges in the Lucidarium (1317-18) ranks among his most important innovations as a music theorist. Like earlier writers, Marchetto distinguished between melodies (cantus) that, relative to their final tones (finales), ranged relatively high (tonus authenticus: authentic mode) and low (tonus plagalis or subiugalis: plagal mode). Unlike previous theorists, Marchetto also allowed for the possibility that a melody's range might be 'mixed' (mixtus), i.e., by virtue of comprising substantial parts of both a high-ranging authentic mode and its low-ranging plagal counterpart. Moreover, within the authentic and plagal categories, Marchetto defined ranges he termed 'perfect' (perfectus: lit. 'complete'), 'imperfect' (imperfectus: relatively narrow), and 'pluperfect' (plusquamperfectus: relatively wide-ranging). Also, Marchetto contrived a way to specify whether an individual melody with a very narrow range (e.g., spanning a sixth or less) should be considered authentic or plagal.

In comparison with earlier accounts, Marchetto's formulation of modal ranges was remarkably comprehensive, tidy and consistent. As well, Marchetto's formulation of melodic ranges can be considered 'deep'-in something like the modern mathematical sense-for it jibes clearly with contrapuntal cadence structures of his era, thus transcending his own important distinction between monophonic chant and polyphonic discant.

Figure 1. Marchetto's formulation of perfect ranges. For perfect authentic modes, the final and lowest notes are underlined; for perfect plagal modes, the confinal and highest notes are underlined.

$\begin{array}{lllll}\text { mode } & \text { final } & \text { lowest note } & \text { highest note } & \text { confinal } \\ \text { 1 authentic } & \underline{\mathrm{D}} & \underline{\mathrm{C}} & \mathrm{d} & \mathrm{a} \\ \text { 2 plagal } & \mathrm{D} & \mathrm{A} & \underline{\mathrm{b}-\mathrm{flat}} & \underline{\mathrm{a}} \\ \text { 3 authentic } & \underline{\mathrm{E}} & \underline{\mathrm{D}} & \mathrm{e} & \mathrm{b} \\ \text { 4 plagal } & \mathrm{E} & \mathrm{B} & \underline{\mathrm{c}} & \underline{\mathrm{b}} \\ \text { 5 authentic } & \underline{\mathrm{F}} & \underline{\mathrm{F}} & \mathrm{f} & \mathrm{c} \\ \text { 6 plagal } & \mathrm{F} & \underline{\mathrm{C}} & \underline{\mathrm{d}} & \underline{\mathrm{c}} \\ \text { 7 authentic } & \underline{\mathrm{G}} & \underline{\mathrm{F}} & \underline{\mathrm{g}} & \mathrm{d} \\ \text { 8 plagal } & \mathrm{G} & \underline{\mathrm{D}} & \underline{\mathrm{e}} & \underline{\mathrm{d}}\end{array}$

\section{Perfect Modes}

Figure 1 displays part of Marchetto's highly ramified account of the modal ranges. In Marchetto's account, an authentic perfect melody extends upward to the note a perfect octave above the final, but its lowest note is not the final-instead its lowest note is a 
major second, i.e., a whole tone, below the final. ${ }^{1}$ Conversely, a perfect plagal melody ranges downward to a note a perfect fourth below the final, but its highest note is not a perfect fifth above the final - rather its highest note is a second above the fifth above the final, that is, a sixth above the final. In other words, a perfect plagal mode ranges from a second above its confinal to an octave below its confinal.

Marchetto's formulation is entirely symmetrical. In general, whatever holds for an authentic mode relative to the final, holds in the opposite direction for a plagal mode relative to the confinal. Authentic modes are perfect, imperfect, and pluperfect in ascent in a manner that is the mirror opposite of the way in which plagal modes are perfect, imperfect and pluperfect in descent.

Figure 2. Marchetto's formulation of ranges that are imperfect in ascent and descent. The final and lowest notes of authentic modes that are imperfect in descent are underlined; conversely, the confinal and highest notes of plagal modes that imperfect in ascent are underlined.

$\begin{array}{lllll}\text { mode } & \text { final note } & \begin{array}{l}\text { lowest note } \\ \text { if imperfect } \\ \text { in descent }\end{array} & \begin{array}{l}\text { highest note } \\ \text { if imperfect } \\ \text { in ascent }\end{array} & \text { co } \\ \text { 1 authentic } & \underline{\mathrm{D}} & \underline{\mathrm{D}} & \mathrm{c} & \mathrm{a} \\ \text { 2 plagal } & \frac{\mathrm{D}}{\mathrm{B}} & \underline{\mathrm{a}} & \underline{\mathrm{a}} \\ \text { 3 authentic } & \underline{\mathrm{E}} & \underline{\mathrm{E}} & \mathrm{d} & \mathrm{b} \\ \text { 4 plagal } & \mathrm{E} & \mathrm{C} & \underline{\mathrm{b}} & \underline{\mathrm{b}} \\ \text { 5 authentic } & \underline{\mathrm{F}} & \underline{\mathrm{F}} & \mathrm{e} & \mathrm{c} \\ \text { 6 plagal } & \mathrm{F} & \underline{\mathrm{D}} & \underline{\mathrm{g}} & \underline{\mathrm{c}} \\ \text { 7 authentic } & \underline{\mathrm{G}} & \underline{\mathrm{G}} & \underline{\mathrm{d}} & \underline{\mathrm{d}} \\ \text { 8 plagal } & \mathrm{G} & \mathrm{D} & \underline{\mathrm{e}}\end{array}$

\section{Imperfect, Pluperfect and Mixed Modes}

Figure 2 shows how Marchetto's framework deals with authentic and plagal modes he considers imperfect in ascent and/or descent. As with perfect modes, imperfect authentic modes form a mirror image with imperfect plagal modes, the mirror corresponding to the final and confinal.

In Marchetto's theory, authentic modes might be 'more than perfect,' that is, 'pluperfect,' but only in ascent, and correspondingly, plagal modes might be pluperfect, but only in descent (Figure 3). This difference appears to be a by-product of Marchetto's general understanding of the contrast between authentic and plagal. What is most characteristic of an authentic melody is that it rises far above its final, whereas a plagal melody characteristically falls far below its final.

\footnotetext{
${ }^{1}$ The seeming anomaly in mode 5, which does not descend a step below its final, is discussed below.
} 
Figure 3. Marchetto's formulation of pluperfect ranges.

\begin{tabular}{|c|c|c|c|c|}
\hline mode & final note & $\begin{array}{l}\text { lowest note } \\
\text { if pluperfect } \\
\text { in descent }\end{array}$ & $\begin{array}{l}\text { highest note } \\
\text { if pluperfect } \\
\text { in ascent }\end{array}$ & confinal \\
\hline 1 authentic & $\underline{\mathrm{D}}$ & & e or $\mathrm{f}$ & $\mathrm{a}$ \\
\hline 2 plagal & $\mathrm{D}$ & $\mathrm{GG}$ or $\mathrm{FF}^{*}$ & & $\mathrm{a}$ \\
\hline 3 authentic & $\underline{E}$ & & f or $g$ & $\mathrm{~b}$ \\
\hline 4 plagal & $\overline{\mathrm{E}}$ & A or $\mathrm{GG}$ & & $\mathrm{b}$ \\
\hline 5 authentic & $\underline{F}$ & & g or $a^{\prime}$ & c \\
\hline 6 plagal & $\overline{\mathrm{F}}$ & $\mathrm{B}$ or $\mathrm{A}$ & & $\mathrm{c}$ \\
\hline 7 authentic & $\underline{\mathrm{G}}$ & & $a^{\prime}$ or b' & $\mathrm{d}$ \\
\hline 8 plagal & $\overline{\mathrm{G}}$ & $\mathrm{C}$ or $\mathrm{B}$ & & $d$ \\
\hline
\end{tabular}

* FF, a whole tone below G-gamma-ut, was not generally used in the gamut until after Marchetto's time. However, FF was employed during the following two centuries, when Marchetto's influence on modal theory was greatest. As well, its counterparts in instances where mode 2 would be transposed 'upward' - though there was no absolute, 'concert' pitch until long after the Middle Ages - to end on $\mathrm{G}$ or a, namely, B-flat and $\mathrm{C}$, were available in the gamut Marchetto employed.

Nonetheless, Marchetto appears to have been well aware that, for example, a melody might rise only to the seventh above its final and yet might descend as far as the third below its final. To deal with such situations, Marchetto introduced the notion that a melody can mix authentic and plagal characteristics. For Marchetto, a mixed melody's ascent might be, on one hand, perfect, imperfect, or pluperfect relative to the authentic norm, and on the other hand, perfect, imperfect, or pluperfect relative to the plagal norm.

In short, Marchetto's treatment of modal ranges was unprecedentedly comprehensive in that it could deal unambiguously with virtually any melody in the tradition of medieval chant. Indeed, so compelling was Marchetto's formulation of melodic ranges that many of the most important theorists of the next two centuries, especially Italians, adopted it with little or no modification. Among the most famous theorists who adopted his formulation during the following two and half centuries were Ugolino of Orvieto, Johannes Tinctoris, Johannes Carthusiensis, Nicolaus Burtius, Franchinus Gafurius, Bonaventura da Brescia, Pietro Aron, and several anonymous writers (e.g., LaFage 7). ${ }^{2}$

Although Marchetto's influence on subsequent terminologies for modal range has long been acknowledged, not only the specific symmetry of his formulation of authentic and plagal has been ignored but also the sources of the terms and concepts in which he framed his novel and influential framework. In this regard, Marchetto's fundamental distinction between authentic and plagal is most important.

\footnotetext{
${ }^{2}$ On theorists influenced by Marchetto's terms for melodic range, see Niemöller (1956).
} 
Figure 4. Contrasts between terms and concepts Marchetto associated with 'authentic' and 'plagal.' Square brackets indicate characterizations that are implied by, rather than explicitly employed in, Marchetto's theory.

odd number (numerus impar)

ascent, elevation (ascensus, elevatio)

worthier (dignior)

nobler (nobilior)

[conquering, imperial]

original (primitus)

[principal]

Greek and Latin numeration even number (numerus par)

descent, fall (descensus,

depositio)

[less worthy]

[less noble]

subjugated (subigualis)

[subsequent, derivative]

residual (reliqui)

Latin numeration only

Terms and Concepts in Marchetto's Contrast between Authentic and Plagal Ranges Figure 4 summarizes the contrasts between terms and concepts Marchetto associated with authentic and plagal ranges. Central to these contrasts are two notions Marchetto received from earlier writers.

From previous medieval music theorists, Marchetto inherited the traditional Latin terms for ordinal numbers to designate particular authentic and plagal modes: the odd numbers 'first,' 'third,' 'fifth,' and 'seventh' (primus, tertius, quintus, and septimus) for authentic modes, and the even numbers 'second,' 'fourth,' sixth,' and 'eighth' (secundus, quartus, sextus, and octavus) for plagals. To this distinction between odd and even numbers, Marchetto joined contrasts, opposites, dichotomies, and polarities that such writings as Aristotle's Metaphysics conveyed to the late European Middle Ages from their sources in pre-Socratic lore.

Figure 5. Coordinated contrasts in Aristotle's Metaphysics (I, 5). Terms in the left column are associated with each other, as are their opposites or complements in the right column.

$\begin{array}{ll}\text { odd } & \text { even } \\ \text { limited } & \text { unlimited } \\ \text { unity } & \text { plurality } \\ \text { right } & \text { left } \\ \text { male } & \text { female } \\ \text { rest } & \text { motion } \\ \text { straight } & \text { crooked } \\ \text { light } & \text { darkness } \\ \text { good } & \text { evil } \\ \text { square } & \text { oblong }\end{array}$

Figure 5 displays the ten coordinated contrasts that had been advanced by earlier, Pythagorean writers, as reported in Aristotle's Metaphysics. The terms and concepts Marchetto associated with odd and even numbers show the extent to which his contrasts 
between authentic and plagal were traditional and conventional - albeit highly gendered and undoubtedly offensive from a modern point of view. These appear in Figure 6.

Figure 6. Terms and concepts Marchetto associates with 'odd' and 'even' numbers. Square brackets enclose characterizations that are implicit in Marchetto's account of the opposite entry.

odd number (numerus impar)

indivisible [into two equal parts]

(indivisibilis)

contains a unit in its middle that

resists division

[immutable]

greater virtue (maior virtus)

[stronger, masculine sex]

male (mas) even number (numerus impar)

divisible [into two equal parts]

(divisibilis)

[does not contain a unit in its middle that resists division]

mutable (mutabilis)

[less virtue]

weaker, feminine sex

[female]

Remarkable in Marchetto's account is the degree to which he elaborates such contrasts. In this Marchetto was also arguably traditional. Indeed, as Aristotle relates later in the chapter of the Metaphysics where his list of ten Pythagorean contrasts appears, Alcmaeon of Croton was very ad hoc and imprecise in his use of dichotomies, saying that:

... the majority of things in the world of men are in pairs; but the contrasts which [Alcmaeon] mentions are not, as in the case of the Pythagoreans, carefully defined, but are taken at random, e.g., white and black, sweet and bitter, good and bad, great and small. Thus Alcmaeon threw out only vague hints with regard to the other instances of contrariety.

Whereas Aristotle says that Alcmaeon's contrasts were 'taken at random,' Marchetto cited what he called 'causa significationis' as a quasi-Aristotelian 'cause' or reason for framing a particular contrast in a certain way: significatio, that is, meaning, or more precisely in Marchetto's usage, connotative, associative, or even Pythagorean, numerological, or cosmological meaning.

\section{'Perfect' and 'Imperfect' as Contrasting Terms and Concepts}

In this manner, Marchetto extended applications of the contrast between odd and even beyond the authentic/plagal distinction. Most important, Marchetto developed a cognate contrast between things that are perfect and things that are imperfect. This contrast permeates not only the Lucidarium but also his other major treatise, the Pomerium. Not only does Marchetto consider certain melodic ranges to be perfect or imperfect, but also particular musical intervals tuned on the monochord and sung in discant (i.e., counterpoint), as well as specific kinds of musical mensuration-or to use an approximate modern term, musical metre.

For instance, as Figure 7 summarizes, in Marchetto's conception, consonances might be perfect or imperfect. Most important, among the perfect consonances, those with the odd- 
numbered proportion $3: 2$, namely, the perfect 5 ths, are more perfect than the perfect 4 ths, which have the even-numbered proportion $4: 3$.

\section{Figure 7. Contrasts Marchetto associates with the perfect fifth and perfect fourth}

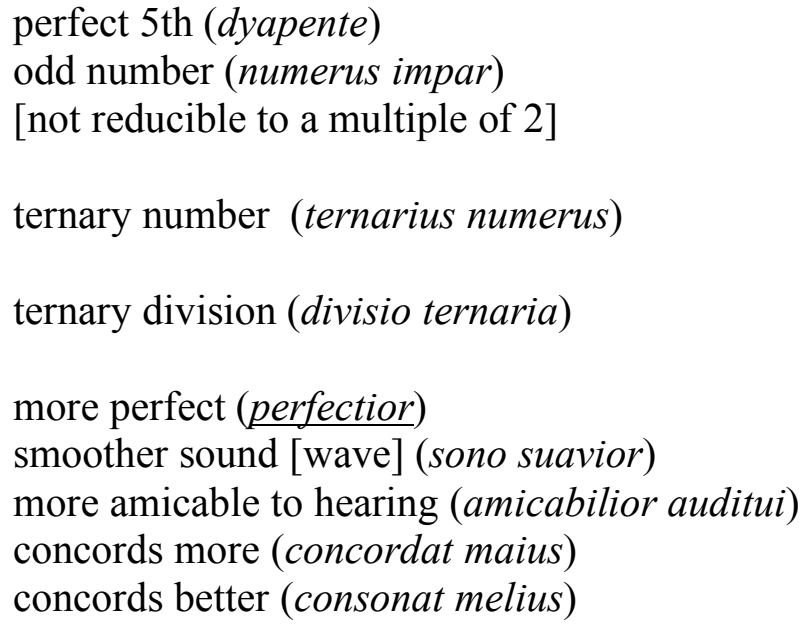

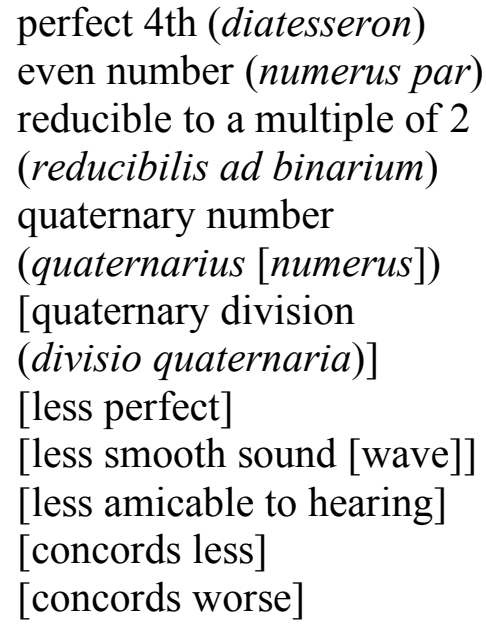

Similarly, the Pomerium, Marchetto's innovative treatise on musical mensuration, contrasts the division of a breve into $3 \times 2$ semibreves with its division into $2 \times 3$ semibreves. For Marchetto, the $3 \times 2$ division, which involves 3 groups of 2 semibreves, is the [divisio] senaria perfecta and the $2 \times 3$ division into 2 groups of 3 semibreves is the [divisio] senaria imperfecta. Here the upper level of the hierarchical framework, the level that comprises the greatest duration, is decisive in characterizing one division as perfect and the other as imperfect.

\section{'Pluperfect' as a Term and Concept}

The terminological source for Marchetto's use of the word 'pluperfect' is obviously the canonic Latin grammar of medieval textbooks, e.g., Donatus. To be sure, the connection between the tense of a verb in grammar and the range of a melody in music might seem obscure. However, the distinction between one modal melodic range, A, that is complete and another, $\mathrm{B}$, that is more than complete can be understood as analogous to the contrast between an action or state, A, that is complete and an action or state, B, that was complete before the time of action or state A.

Within Marchetto's theory as a whole, one can discern a further reason for his use of the term 'pluperfect' in his notion that a perfect fifth is 'more perfect' than a perfect fourth. That one thing can be more perfect than another opens a door to one thing being simply more than perfect: literally, 'plusquamperfectus.'

Indeed, to be more than perfect need not imply that something is too perfect, that it has an Aristotelian 'excess' of perfection. For perfection might only imply enough of something, and pluperfection more than enough, but not necessarily too much. Or a perfect thing 
might simply be considered complete, an imperfect thing incomplete, and a pluperfect thing more than complete-but not necessarily too complete.

In fact, Marchetto places a constraint on pluperfection. As Figure 3 (above) shows, and as Marchetto states explicitly, a pluperfect authentic might rise a ninth or tenth above its final, and correspondingly, a pluperfect plagal might descend a fifth or sixth below its final. In short, as Figure 3 shows, there are determinate boundaries on pluperfection: a tenth above the final and a tenth below the confinal. Similarly, there are clear boundaries between perfection and imperfection. These boundaries are between the sixth and seventh degrees above the final, and between the sixth and seventh degrees below the confinal.

That Marchetto's analogies among melodic range, musical intervals, and musical metre could be even further elaborated is evidenced by such later Trecento writers on mensuration as Johannes Vetulus de Anagnia and Pietro da Amalfi, who followed both Marchetto and Philippe de Vitry. Whereas the anonymous writer of the Fragmentum de mensuris promulgated the Marchettan rhythmic contrast between perfect and imperfect senaria, Marchetto's disciple Pietro went even further by specifying durations that were perfecti, imperfecti, and imperfectissimi. ${ }^{3}$ Indeed, among treatises immediately influenced by Marchetto's formulation of mensuration, Vetulus's Liber de Musica seems to have gone the farthest of all.

On the basis of atomic temporal units (athomi), each lasting about one-seventh of a second (i.e., approximately M.M. atom = 420), Vetulus developed no fewer than 30 kinds of metre, in which the individual 'measures,' as it were, range in duration from 3 to 864 atoms. Of direct relevance to Marchetto's way of theorizing, Vetulus employed a unified set of proportions, graduated between longer and shorter durations. He arranged these according to the following ordered arrays of mensural adjectives: a) perfectus, imperfectus, semi-perfectus, semi-imperfectus; b) larga, semi-larga, duplex longa, longa; c) maius, minus, minimum. Within each group of two or three metres that are designated by a particular subset of these adjectives, the largest measures are uniformly perfect. Indeed, the entire hierarchical scheme hinges on distinctions between perfect and imperfect, which involve a contrast between triple and duple, and on gradations from largest to smallest. ${ }^{4}$

\section{An Apparent Anomaly: Mode 5 Perfect in Descent}

The generality with which Marchetto employed the contrast between perfection and imperfection serves to explain the way in which he accounts for a longstanding anomaly among the authentic modal ranges. Toward the end of the 9th century, the Alia musica said that mode-5 melodies, unlike other authentic modes, do not descend a scale degree below their finals. Adopting an empirical outlook, Guido's Micrologus (ca, 1020) claimed that such a descent to E below F was 'rare.' What we know of Gregorian chant

${ }^{3}$ On Pietro and the Fragmentum, see Gallo (1966), pp. 72 and 77.

${ }^{4}$ On Vetulus's mensurations, see Hammond's edition (1977), pp. 21-22. 
corroborates Guido's observation. However, such an empirical generalization begs the question of how one can explain this rarity systematically.

Marchetto's explanation is that E is not the lowest note in a 5th-mode melody because E forms an imperfect inteval with F. Considered in isolation from the rest of Marchetto's theory, this explanation might seem ad hoc rather than systematic. However, for Marchetto the semitone between $\mathrm{E}$ and $\mathrm{F}$ is imperfect in the sense that it is only a part of (semi-) a whole tone, that is, an incomplete whole tone, and in his theory perfect things are more privileged than imperfect things. To be sure, Marchetto recognizes as perfect a plagal melody in the 2 nd or 4 th mode that ascends to a semitone above its confinal, and a 5th-mode melody that ascends to the perfect octave above its final, which forms a semitone with high e: respectively, b-flat above $\mathrm{a}, \mathrm{c}$ above $\mathrm{b}$, and $\mathrm{f}$ above e. However, Marchetto's hierarchy of privileged entities again 'saves the appearances,' as it were, for within his formulation, a final is of higher theoretical status than a confinal and than the octave above a final, as are authentic ranges in comparison with plagal. In this way, the seeming anomaly of 5th-mode descents is an 'exception that proves the rule.'

\section{Commixed Modes}

In the interest of brevity, I shall not deal in detail here with Marchetto's novel concept of commixed (commixtus) modes, which he groups with his new terms for melodic ranges (perfect, imperfect, etc), even though, strictly speaking, a melody is commixed or not irrespective of its melodic range. ${ }^{5}$ Suffice it to emphasize that this innovation depends, in large measure, on Marchetto's notion that a perfect 5th is 'more perfect' than a perfect 4th.

Briefly put, Marchetto's novel notion of commixture considers melodic passages - as distinguished from whole melodies - to be authentic if the 5th above the final of a mode which differs from the main mode of a particular melody - other than the main mode's plagal or authentic counterpart, a situation that is handled by his idea of modal mixtureis prominent, but plagal if the 4th above the final is emphasized. Further, one can connect this dichotomy to his general contrast between ascent and descent insofar as a note that is a 5 th above the final is farther above the final than a note that is a 4 th above.

By way of a sequence of transmission that seems not yet to have been traced in detail, contrasts which musicians drew several centuries later, and which are still perpetuated without musicological comment in modern harmony textbooks, appear to have their origin in Marchetto's novel formulation of the modes. Dealing with quite a different musical idiom than Marchetto's modes and discant, modern harmony treatises distinguish between cadences that are authentic and plagal, and between cadences that are perfect and imperfect.

On one hand, the Aristotelian contrast between complete and incomplete that underlies the distinction between perfect and imperfect cadences has been conveyed clearly by

\footnotetext{
${ }^{5}$ On Marchetto's theory of commixture, see Rahn (1987).
} 
modern harmony textbooks. By contrast, an understanding of Marchetto's idea that plagal connotes the 4th above the final (or in modern terms, the 4th above the tonic, as in the plagal cadence IV-I) whereas authentic connotes the 5th above (as in the authentic cadence, V-I) persists in modern harmony formulations only in the attenuated association of the term plagal with the relatively recent ecclesiastical convention of setting the word 'Amen' at the end of a hymn to a succession of subdominant and tonic triads. Nevertheless, one can step even farther outside Marchetto's immediate historical context by comparing his account of modal ranges with recent attempts at systematizing discant, i.e., dyadic modality.

Figure 8. Voice-leading in dyadic modality (cf. Boretz 1970 and Rahn 1997). Arrows indicate resolution: e.g., ' $\mathrm{x} \rightarrow \mathrm{y}$ ' represents ' $\mathrm{x}$ is resolved by $\mathrm{y}$.' Horizontal brackets indicate 'voices,' i.e., sub-registers within an octave.

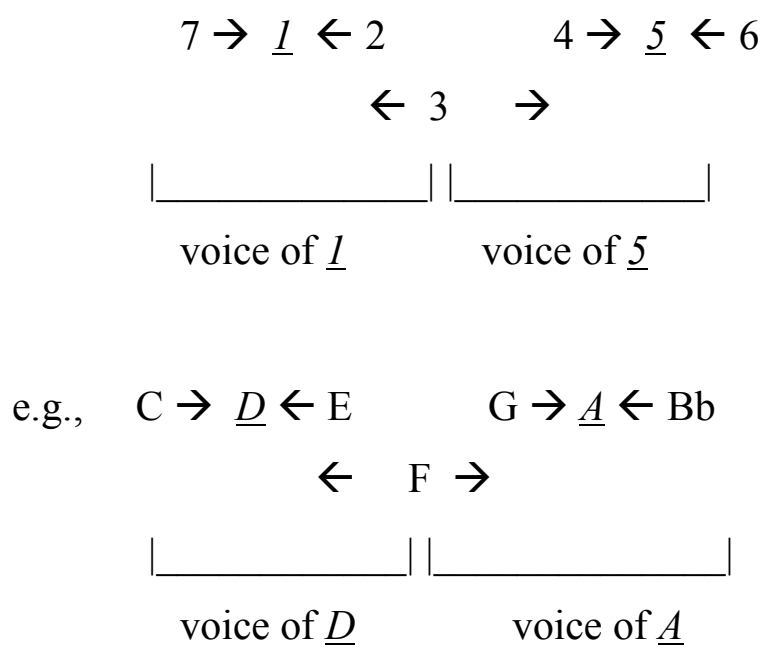

\section{Modal Symmetry, Discant Cadences, and the Corda}

In the voice-leading scheme of Figures 8 and 9, the boundary between degrees 7 and $6-$ which is the boundary between authentic and plagal in both registers of Marchetto's formulation - corresponds to the boundary between the 'voice' (or sub-register) of the final and the voice of the confinal. As well, degree 3-which is not only the neutral, uncounted corda in Marchetto's formulation of melodies having a very narrow range, ${ }^{5}$ but also the upper boundary of authentic pluperfect and the lower boundary of plagal pluperfect - comprises the upper boundary of the final's sub-register and the lower boundary of the confinal's sub-register.

That the corda is a medial scale degree seems to have its roots in the Alia musica's account of the 'chorda.' In the Alia musica, an authentic mode's octave species (e.g., from d to d' in Dorian, 1st-mode melodies) is mediated by the scale degree a perfect 5th above the final (e.g., in 1st mode, a above d). In the Alia musica, the final and scale degrees a perfect 5th and a perfect octave above the final (e.g., d, a, and d' in Dorian) are formulated numerically as string lengths. 
Figure 9. Sub-registral boundaries of modes 1 and 2 in Marchetto's theory of modal ranges, compared with the dyadic 'voices' of Figure 8

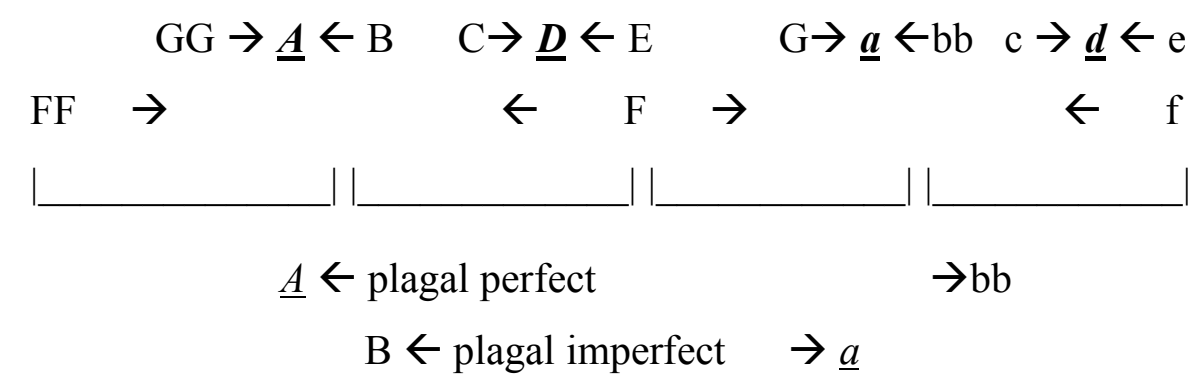

FF $\leftarrow$ plagal pluperfect

$$
\begin{aligned}
\mathrm{C} \leftarrow \text { authentic perfect } & \rightarrow \underline{d} \\
\underline{D} \leftarrow \text { authentic imperfect } \rightarrow \mathrm{c} & \\
\text { authentic pluperfect } & \rightarrow \mathrm{f}
\end{aligned}
$$

The Alia musica's string lengths correspond to the proportions for the harmonic mean of classical antiquity: 12:8:6, which correspond to the frequency proportions $2: 3: 4$, which, in turn, correspond to $\mathrm{d}$, a a perfect 5 th above $\mathrm{d}$, and d' a perfect 4 th above a and perfect octave above d. Whereas the Alia musica's chorda corresponds to both a particular string and the middle of an authentic mode's octave, Marchetto's use of the term corda refers not to a string, but to a particular scale degree that is at the middle of the privileged interval of a perfect 5 th between a mode's final and confinal.

That Marchetto's formulation of authentic and plagal modes accords greater privilege to a mode's confinal, a perfect 5th above its final, than to the perfect 4 th above the final corresponds to a large-scale shift that took place between early European polyphony and the discant of Marchetto's time. ${ }^{6}$ Whereas perfect 4ths and perfect 5ths above the lowest sounding tone in a sonority had been treated as similarly consonant, by Marchetto's period only the perfect 5th continued to served this function. In this way, Marchetto's view that perfect 5ths are more perfect than perfect 4ths is of consequence not only for modal melodies but also for polyphonic practice.

\section{Conclusion}

In sum, Marchetto's contributions to medieval music theory's 'research programme'- to borrow a notion from Imre Lakatos - involved an unprecedentedly systematic attempt at unification that comprised modal melody as well as the mensuration and discant or counterpoint of polyphony. A means to this end was to make new use of existing terms and concepts. In this, Marchetto's employment of terms resembles some forms of technical jargon during the past century of Euro-American scholarship: ad hoc and

${ }^{6}$ On the significance of Marchetto's distinction between perfect 4ths and 5ths above the 'bass,' see Rahn (1978, 1981). 
neologistic. Marchetto's repeated specification of different meanings for a single term within contrasting regions of a single system (e.g., 'perfect' and, in other portions of the Lucidarium, 'chromatic,' 'enharmonic,' 'diatonic,' and 'diesis') ${ }^{7}$ might mark his effort at theoretical unification somewhat alien to modern approaches to theory construction. All the same, if Marchetto did not construct a modal and polyphonic 'world' in the modern

sense of Frege, Hilbert, Russell, Carnap, or Goodman, he nonetheless formulated concepts relevant to music of his day in a manner that is readily deconstructed.

\section{REFERENCES CITED}

Anonymous. Alia musica. trans., ed. Jacques Chailley. Paris: Centre de documentation universitaire, 1965

Anonymous. Donatus Ortigraphus: Ars grammatica. ed. John Chittenden. Turnholti: Brepols. 1982

Aristotle. The Metaphysics. trans. with Greek and Latin glosses, Hugh Lawson-Tancred. London: Penguin, 1998; online trans. W.D. Ross. Raleigh, N.C.: Alex Catalogue. 2000 (online)

Boretz, Benjamin. Sketch of a Musical System (Meta-Variations, Part II). Perspectives of New Music, 8 (1970), 49-111

Gallo, F. Alberto. La teoria della notazione in Italia dalla fine del XIII all'inizio del XV secolo. Bologna: Tamari. 1966

Herlinger, Jan, ed., trans. The Lucidarium of Marchetto of Padua. Chicago: University of Chicago Press.1985; online version of Latin text at www.chmtl.indiana.edu/tml/14th/14TH INDEX.html (accessed Oct. 23, 2006)

Lakatos, Imre. The Methodology of Scientific Research Programmes, vol. 1. ed. John Worrall and Gregory Currie. Cambridge, UK; Cambridge University Press, 1978.

Marchettus of Padua. Pomerium in arte musice mensurate. ed. Giuseppe Vecchi, Corpus Scriptorum de Musica, 6 (1961)

Niemöller, Klaus Wolfgang. Zur Tonus-Lehre der italienischen Musiktheorie des ausgehenden Mittlelalter. Kirchenmusikalisches Jahrbuch 60 (1956), 23-32

Rahn, Jay. Constructs for Modality, ca. 1300-1550. Canadian Association of University Schools of Music Journal 8/2 (1978), 5-39

. Ockeghem's Three-Section Motet Salve Regina : Problems in Coordinating Pitch and Time Constructs. Music Theory Spectrum 3 (1981), 117-31 . Marchetto's Theory of Commixture and Interruptions. Music Theory Spectrum 9 (1987), 117-35 . Recent Diatonic Theory and Curwen's Tonic Sol-Fa Method: Formal Models for a Kinesic-Harmonic System. Proceedings of the Third Triennial Conference of the European Society for the Cognitive Sciences of Music (ESCOM), Uppsala Universitet (1997), 134-39

. Practical Aspects of Marchetto's Tuning. Music Theory Online, 4/6 (1998): http://boethius.music.ucsb.edu/mto/issues/mto.98.4.6/mto.98.4.6.rahn.html (accessed Oct. 23, 2006)

7 On Marchetto's use of the terms 'chromatic,' 'enharmonic,' 'diatonic,' and 'diesis' the latter especially important for his concept of the corda - see Rahn (1998). 
Vetulus de Anagnia, Johannes. Liber de musica. ed. Frank Hammond (Corpus Scriptorum de Musica 27). Rome: American Institute of Musicology, 1977 